\title{
Proceeding
}

Supplementary Issue: Spring Conferences of Sports Science. Costa Blanca Sports Science Events, 14-15 June 2019. Alicante, Spain.

\section{A wheelchair by the overboard model: A technological instrument for disabled basketball players}

\author{
STEFANIA BOCCIA 19 , RICCARDO IZZO², FRANCESCA D'ELIA ${ }^{1}$, SIMONA FATTORE ${ }^{1}$ \\ ${ }^{1}$ University of Salerno, Italy \\ 2University Carlo Bo of Urbino, Italy
}

\begin{abstract}
The aim of the study is to identify a solution to the preliminary study of normal people's capacity of adjustment on a wheelchair in the context of basketball, a solution that fundamentally would also encourage the performance of people with disabilities. As the difficulties encountered in the previous study were mainly on the sitting and on the thrust of the wheelchair, the introduction of the new technological instrument already presented could be useful and meaningful: a chair characterized by the presence of an engine, like the one that distinguishes the electric skateboards of the new millennium, such as overboard and Segway, which work thanks to the displacement of the centre of gravity. Practically, shifting the weight of the bust in all directions (back, forward, right, left) translocations occur in space. Consequently, all this would not only favour the norm gifted athletes who at first impact have many difficulties in the conduction of the wheelchair, but also those who have more or less serious disabilities (especially people with amputation of the upper limbs). In fact, the presence of motor and sensors that allow to move the wheelchair only with the movement of the body centre of gravity, simplifies the performance of sports and makes it less expensive from the point of view of energy, as there would no longer be the need to have to push the mobile device manually. Keywords: Sport inclusion; Adapted rules; Adapted physical activity.
\end{abstract}

\section{Cite this article as:}

Boccia, S., Izzo, R., D'Elia, F., \& Fattore, S. (2019). A wheelchair by the overboard model: A technological instrument for disabled basketball players. Journal of Human Sport and Exercise, 14(4proc), S1080S1086. doi:https://doi.org/10.14198//hse.2019.14.Proc4.71

Corresponding author. University of Salerno, Italy.

E-mail: sboccia96@gmail.com

Supplementary Issue: Spring Conferences of Sports Science. Costa Blanca Sports Science Events, 14-15 June 2019. Alicante, Spain.

JOURNAL OF HUMAN SPORT \& EXERCISE ISSN 1988-5202

(c) Faculty of Education. University of Alicante

doi:10.14198/jhse.2019.14.Proc4.71

S1080 | 2019| Proc4 | VOLUME 14

C 2019 University of Alicante 


\section{INTRODUCTION}

Basketball is one of the most important team sports in the world and, for this reason, many peoples have interest for the development in several way. According to the strategic aspects (Altavilla, Raiola, 2019, 2015, 2014, Alberti et al., 2014, Raiola, D'Isanto 2016), tactical and technical ones (Altavilla et al, 2018abc) are the main such as the performance aim and its tools (Izzo et al 2018, 2017). The technologies can help the disabled athletes in sports activities (D'Elia et al, 2019, Cassese, Raiola, 2017). New technologies in volleyball are widely involve in training process and in competition (Ferrara et al, 2019, 2018ab) but it does not reach the inclusion process among disabled athletes and non-disabled ones (Martino et al, 2019, Pisapia et al, 2019, Pisapia, D'Isanto, 2018). The proposed work aims to identify a solution to the preliminary study on the ability to adapt normal people to a wheelchair. Since the outcome of the previous study (Boccia et al.,2019), mainly focused on basketball and which saw a heterogeneous group of young athletes registered in a regional championship, was negative, a new technological tool was assumed: a wheelchair based on the model of the overboard, an electronic means of transport and a status symbol which characterizes the new generation of the 21 st century. Also the teaching method can have a meaningful influence, especially in team sport (Invernizzi et al, 2019, Montella et al, 2019).

Motor control and learning (Raiola, 2017, Raiola, di Tore, 2017, Raiola, 2013) in wheelchair basket have to deeply study for the uninvestigated aspects both for players and for instrumental tools that have the consequentially inferences in assessment process (D'Isanto et al, 2019, Di Tore et al, 2018). Into the school, inclusion teaching method is currently one of the most priority and physical education could be a natural approach at the issue (Viscione et al, 2019).

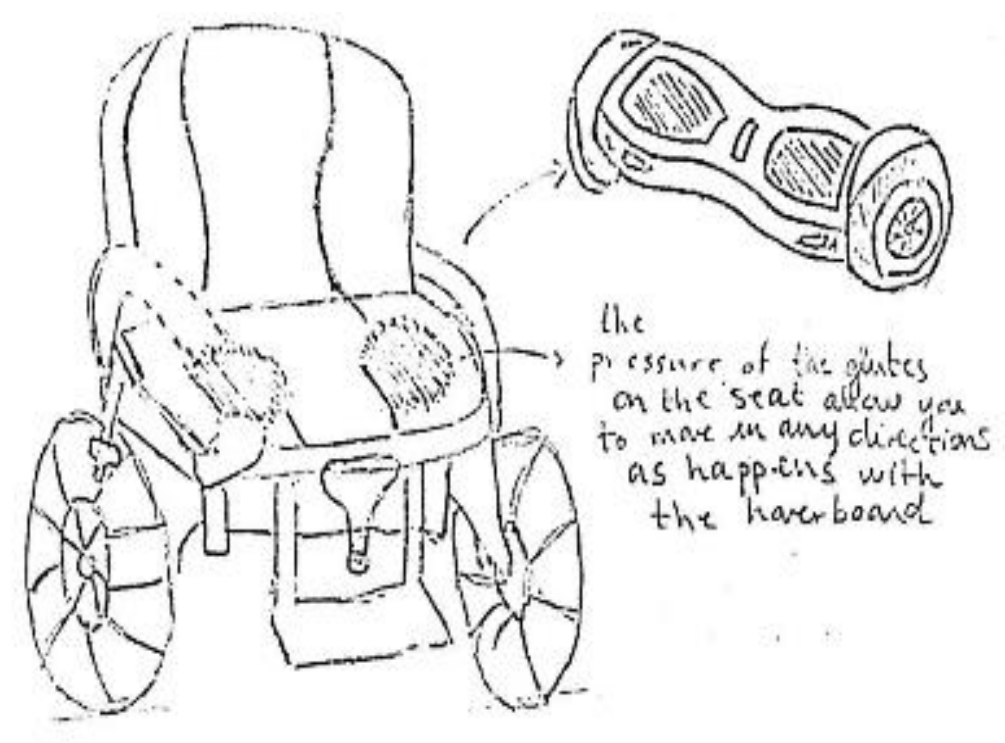

Figure 1. Wheelchair and outside overboard.

The idea of introducing an hypothesis of a mobile device like this, especially in the sports context, was mainly induced by the difficulties that the sample encountered in his first approach to the wheelchair and which he tried, even if not with optimal results, to overcome during the three tests administered based on the performance of the fundamentals of basketball. 
The prototype of this new model differs from the classic wheelchairs and it has some special features:

- It is slightly wider and with wheels characterized by a thicker and wider rubber, so as to be more stable and to avoid overturning during contrasts or changes of direction made at speed;

- It has padding to amortize any type of impact, provided that it is considered lawful by the regulation of the sport in question; it has a safety belt to avoid possible falls from the chair and a footrest;

- The movements from one area to the other of the field take place thanks to the presence of a motor positioned below the chair (not directly visible), and of particular sensors of the overboard; practically, thanks to the pressure of the gluteus and consequently to the displacement of the weight of the bust in every direction (forward, back, right, left) translocations occur in space.

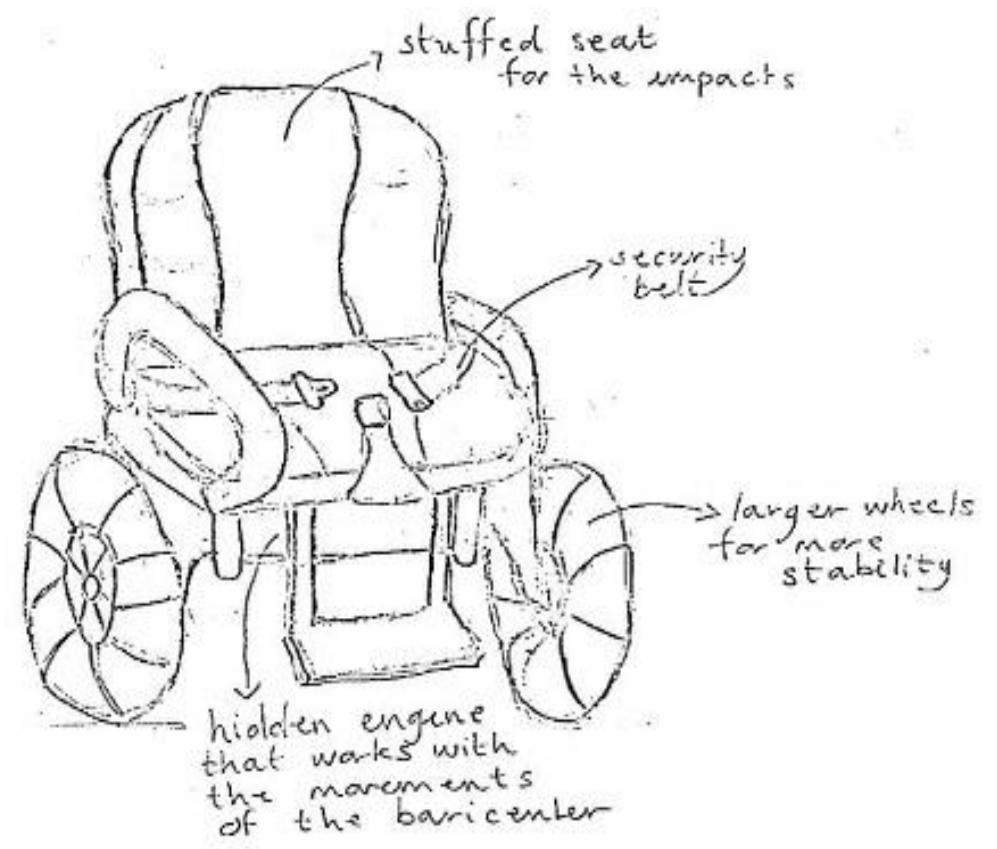

Figure 2. Wheelchair and inside overboard.

\section{THE OVERBOARD MODEL}

The self-balancing electric scooter or self-balancing bicyclic table, mistakenly and commonly known as "overboard" (a term referring to the famous levitating skateboard seen for the first time in Back to the future), was invented in China and introduced on the market in 2014, reaching a greater notoriety in 2015, especially in the USA.

Despite the numerous patent wars involving many companies that mention each other for who invented it before, the real "father" would be the inventor and businessman Shane Chen, who presented his prototype already in 2013.

It is nothing but a personal transport device on which it is necessary to stand, characterized by a very particular functioning: thanks to the displacement of the body weight it is possible to effect translocations in the space. In practice, by moving the weight forward, the overboard will tend to move forward; if the weight is shifted to the right, it will move sideways and in the same way it will also happens for the other directions. 


\section{STRUCTURE OF THE OVERBOARD}

The overboard consists of two wheels well welded to the ground, 6 or 10 inch in diameter, which move thanks to an electric motor powered by a rechargeable battery that normally reaches two hours of battery life.

They are independent of each other, in this way one can go forward and the other backwards, allowing changes of direction and moreover they are connected to two articulated platforms that rotate on the same axis, guaranteeing greater stability and manoeuvrability.

Its technical characteristics may vary depending on the model, but in general this scooter is able to reach a maximum speed of $10 / 12 \mathrm{Km} / \mathrm{h}$ and it has a load capacity that should not exceed $90 \mathrm{~kg}$.

The functioning of the overboard is mainly similar to that of a Segway, the only difference being that the first one does not have a handlebar or a handle to rest the hands. Inside, the device considered has a complex technology: there is a gyroscope, an accelerometer, a logic board and sensors.

However, what really favours its particular functioning is the gyroscope. It is a rotating physical device able to move on its own axis in a peculiar way and it is mainly based on the law of conservation of the angular moment which states that the angular momentum of a system is constant in time if the moment of the external forces acting on it is null.

The gyroscope is widely used in numerous technological tools, especially in mobile phones, bicycles, airplanes, etc., but in the overboard it has the task of verifying its balance when a certain pressure is applied to it.

The signal linked to the latter is received by the sensors located inside the wheels.

These sensors, activated by the weight of the driver when he gets on the scooter, then send the collected information to a control board and to the gyroscope, both situated inside the support platform and then forwarded to the "brain" of the overboard, the logic board.

Subsequently, the signal will be sent to the wheels, allowing the movement of the self-balancing electric scooter.

However, as far as the logic board is concerned, or even called the motherboard, it represents the brain of the device, as it was explained previously and it consists of a processor, which takes care of measuring and evaluating the data of the accelerometer and the gyroscope in real time, preserving balance.

Moreover, although overboards represent an excellent alternative, above all ecological, to move around the city, they can also be particularly dangerous. In fact, since they are often used on the road, although this is not allowed by law, as they are not recognized as real means of transport, they can cause many road accidents and there are also high risks of falling.

Although they do not reach very high speeds, a fall can be dangerous, in particular a fall backwards. So it is always advisable to wear the right precautions, such as helmets, elbow pads and knee pads, to reduce the risk of injury. 
Furthermore, there have also been some cases in which these devices have spontaneously exploded or caught fire in different states of use.

This happens mainly due to the fact that, increasing the popularity and the demand on the market, many manufacturers have dealt with the realization of these self-balancing tables, using lower and cheaper materials, in particular lithium-ion batteries which are installed on the card.

\section{THE PROTOTYPE OF THE NEW WHEELCHAIR: THE PROS}

The prototype of this new wheelchair, already mentioned and described above, is based on the abovementioned overboard model.

The wheelchair functioning considered is the same as the self-balancing scooter: it is assumed that everything that constitutes the "heart and brain" of the latter is inserted and positioned below the seat. However, the most significant difference between the two vehicles is that instead of standing upright and sending signals to the overboard engine with your feet, you will find yourself comfortably seated and the movements will be made exclusively and only through the movement of the bust.

The conception of this new hypothetical wheelchair model was induced by the failure of the previous study on the adaptability of some basketball players to the wheelchair; in this study, they were in significant difficulties in the approach to the latter, especially in the wheel thrust to advance and at the same time dribble.

As a result, it is mainly dedicated to a sports context, with the aim of making it more inclusive and minimizing the differences that might arise between able-bodied and disabled people, as it is assumed that the former may have many more advantages than the others.

In fact, the possibility of using a wheelchair of this type in a sports practice, not only could favour a decrease of the possible injuries especially to the shoulder that could occur during the continuous effort in pushing the wheels of the wheelchair, but could also facilitate the participation of individuals with more or less severe disabilities, such as amputations of the upper limbs.

In fact, being able to exploit the presence of sensors and the functionality of the overboard engine applied to the seat of the wheelchair and consequently, the opportunity to be able to avoid having to push independently, with the strength of the arms, can favour a lower waste of energy and an improvement in sports performance.

\section{CONCLUSIONS}

In conclusion, the introduction of this new prototype would represent a real innovation in the sports world; it would mean not only introducing all the possible pros listed previously, but also adapting the latter to the advancement of technological development that characterizes the new millennium.

However, to allow all the individuals to enjoy the most of this tool, it would be necessary to instruct them to use it.

This could happen by setting up a series of sessions only and exclusively for learning and acquiring all the possible information useful to fully exploit this new technology, which at first glance could be quite complicated, above all to understand and evaluate its functionality, the sensitivity of the sensors dedicated to 
the movements, the speed regulation and so on.

\section{REFERENCES}

Alberti, G., Annoni, M., Ongaro, L., Scurati, R., Michielon, G. (2014) Athletic performance decreases in young basketball players after sitting, International Journal of Sports Science and Coaching, 9 (5), pp. 975-984. https://doi.org/10.1260/1747-9541.9.5.975

Altavilla, G., Raiola, G. (2019) A brief review on physiological commitment in basketball: An interpretative key, Journal of Human Sport and Exercise, 14, pp. S59-S65. https://doi.org/10.14198/ihse.2019.14.proc1.07

Altavilla, G., D'Isanto, T., Di Tore, A.P., Raiola, G. (2018a) Free throw and outcomes: Pilot study on intensive training versus extensive one, Journal of Human Sport and Exercise, 13 (3), pp. 494-503. https://doi.org/10.14198/jhse.2018.133.02

Altavilla, G., D'Elia, F., Raiola, G. (2018b) A breif review of the effects of physical activity in subjects with cardiovascular disease: An interpretative key, Sport Mont, 16 (3), pp. 103-106.

Altavilla, G., Gaetano, R. (2018) Physiological effects of warm-up and problems related to team sports, Sport Science, 11, pp. 83-88.

Altavilla, G., Raiola, G. (2015) Sports game tactic in basketball [Sport Science, 8 (1), pp. 43-46.

Altavilla, G., Raiola, G. (2014) Global vision to understand the game situations in modern basketball, Journal of Physical Education and Sport, 14 (4), art. no. 75, pp. 493-496.

Altavilla, G., D'isanto, T., Di Tore, P.A. (2018c) Anthropometrics characteristics and jumping ability in basketball, Journal of Human Sport and Exercise, 13, pp. S385-S392. https://doi.org/10.14198/ihse.2018.13.proc2.22

Cassese, F.P., Raiola, G. (2017) The importance of sport in disability management, Sport Science, 10, pp. 7-11.

D'Isanto, T., D'Elia, F., Raiola, G., Altavilla, G. (2019) Assessment of sport performance: Theoretical aspects and practical indications, Sport Mont, 17 (1), pp. 79-82.

Di Tore, A.P., Raiola, G., D'Isanto, T. (2018) Situation awareness in sports science: Beyond the cognitive paradigm [Situacijska svijest u sportskoj nauci: Van kognitivne paradigme]Sport Science, 11 (1), pp. 44-48.

Ferrara, F., Izzo, R., Ceciliani, A., Di Tore, A.P. (2019b) Pilot study on the testing of Power Glove applied to volleyball, Journal of Human Sport and Exercise, 14 (Proc2), pp. S233-S238. https://doi.org/10.14198//hse.2019.14.proc2.11

Ferrara, F., Di Tore, P.A., Gaetano, R. (2018) Preliminary work on the testing of power glove applied to volleyball, Journal of Physical Education and Sport, 18, art. no. 294, pp. 1986-1990.

Invernizzi, P.L., Crotti, M., Bosio, A., Cavaggioni, L., Alberti, G., Scurati, R. (2019) Multi-teaching styles approach and active reflection: Effectiveness in improving fitness level, motor competence, enjoyment, amount of physical activity, and effects on the perception of physical education lessons in primary school children, Sustainability (Switzerland), 11 (2). https://doi.org/10.3390/su11020405

Izzo, R., Varde'i, C.H. (2018) Experimental approach via three different protocols on the speed agility in basketball: A case study, Journal of Physical Education and Sport, 18 (2), art. no. 93, pp. 637-640.

Izzo, R., Bertoni, M. (2017) Analysis of biomechanical abilities of basketball players through the use of a k-track device, Sport Science 10, pp. 34-41.

Martino, L., Fonzo, E., Cassese, F.P., D'isanto, T. (2019) Principles of adaptation of the rules for disabled athletes for an inclusion sport, Journal of Human Sport and Exercise, 14 (Proc2), pp. S215-S220. https://doi.org/10.14198/ihse.2019.14.proc2.08 
Pisapia, F., D'Isanto, T. (2018) Inclusive methods of adaptive training in sprints: A theoretical preliminary study, Journal of Physical Education and Sport, 18, art. no. 316, pp. 2101-2105.

Raiola, G., D'elia, F., Altavilla, G. (2018) Physical activity and sports sciences between European Research Council and academic disciplines in Italy, Journal of Human Sport and Exercise, 13, pp. S283-S295. https://doi.org/10.14198/ihse.2018.13.proc2.13

Raiola, G. (2017) Motor learning and teaching method, Journal of Physical Education and Sport, 17, art. no. 236, pp. 2239-2243.

Raiola, G., Di Tore, P.A. (2017) Motor learning in sports science: Different theoretical frameworks for different teaching methods, Sport Science, 10, pp. 50-56.

Raiola, G., D'isanto, T. (2016) Descriptive shot analysis in basketball, Journal of Human Sport and Exercise, 11 (Proc1), pp. S259-S266. https://doi.org/10.14198/jhse.2016.11.proc1.18

Raiola, G. (2013) Body knowledge and motor skills, Knowledge Cultures, 1 (6), pp. 64-72.

\section{@(@) $\Theta \Theta$}

This work is licensed under a Attribution-NonCommercial-NoDerivatives 4.0 International (CC BY-NC-ND 4.0). 